\title{
B2-spectrin depletion impairs DNA damage repair
}

\author{
Nobuo Horikoshi',2, Raj K. Pandita ${ }^{1,2}$, Kalpana Mujoo ${ }^{1}$, Shashank Hambarde ${ }^{1,3}$, \\ Dharmendra Sharma ${ }^{1}$, Abid R. Mattoo ${ }^{1}$, Sharmistha Chakraborty ${ }^{1,2}$, Vijaya \\ Charaka $^{1}$, Clayton R. Hunt ${ }^{1,2}$ and Tej K. Pandita ${ }^{1,2}$ \\ ${ }^{1}$ Department of Radiation Oncology, Houston Methodist Research Institute, Houston, TX, USA \\ 2 Department of Radiation Oncology, University of Texas Southwestern Medical School, Dallas, TX, USA \\ ${ }^{3}$ Department of Microbiology and Molecular Genetics, McGovern Medical School, University of Texas Health Science Center \\ at Houston, Houston, TX, USA \\ Correspondence to: Tej K. Pandita, email: tpandita@houstonmethodist.org \\ Keywords: $\beta 2$-spectrin, genotoxicity, DNA repair \\ Received: April 11,2016 Accepted: May 20, $2016 \quad$ Published: May 27, 2016
}

\section{ABSTRACT}

$\beta 2-S p e c t r i n$ ( $\beta 2 S P / S P T B N 1$, gene SPTBN1) is a key TGF- $\beta /$ SMAD3/4 adaptor and transcriptional cofactor that regulates TGF- $\beta$ signaling and can contribute to liver cancer development. Here we report that cells deficient in $\beta 2-S p e c t r i n$ ( $\beta 2 S P$ ) are moderately sensitive to ionizing radiation (IR) and extremely sensitive to agents that cause interstrand cross-links (ICLs) or replication stress. In response to treatment with IR or ICL agents (formaldehyde, cisplatin, camptothecin, mitomycin), B2SP deficient cells displayed a higher frequency of cells with delayed $\mathrm{Y}-\mathrm{H} 2 \mathrm{AX}$ removal and a higher frequency of residual chromosome aberrations. Following hydroxyurea (HU)induced replication stress, $\beta 2$ SP-deficient cells displayed delayed disappearance of Y-H2AX foci along with defective repair factor recruitment (MRE11, CtIP, RAD51, RPA, and FANCD2) as well as defective restart of stalled replication forks. Repair factor recruitment is a prerequisite for initiation of DNA damage repair by the homologous recombination (HR) pathway, which was also defective in $\beta 2 S P$ deficient cells. We propose that $\beta 2 S P$ is required for maintaining genomic stability following replication fork stalling, whether induced by either ICL damage or replicative stress, by facilitating fork regression as well as DNA damage repair by homologous recombination.

\section{INTRODUCTION}

Maintaining genomic stability is important for an organism throughout its lifetime in order to protect against the development of cancer. Alcohol-related genotoxicity, arising from DNA damage by metabolically generated reactive aldehydes, has recently been observed in animal models containing inactivation of genes in the Fanconi anemia pathway [1]. Specifically, Fanc mutant mice crossed with Aldh2-mutant mice are susceptible to ethanol-induced teratogenicity and display defective DNA interstrand cross-link repair [1]. Yet, alcohol-treated mice with the Fanc mutation alone do not develop fetal alcohol syndrome-like aberrations, suggesting the importance of genotoxic acetaldehyde in a complex process of toxininduced DNA damage [2-5]. Transforming growth factor $\beta$ (TGF- $\beta$ ) is a critical protein in the regulation of several cancer phenotypes [6] and keratinocytes of TGF $\beta 1$-null mice exhibit genomic instability [8]. TGF- $\beta$ also functions as an extracellular sensor of IR-induced cell damage [7] and this function along with numerous other TGF- $\beta$ actions are initiated through binding to the TGF- $\beta$ receptor I and TGF- $\beta$ receptor II serine-threonine kinase receptors, followed by activation, phosphorylation, and nuclear translocation of receptor regulated SMAD3 and SMAD2. The latter form complexes with the common mediator SMAD4 and subsequently activate TGF- $\beta$ target genes [9]. Recent studies of Smad4 knockout mice, that develop head and neck cancers, demonstrated a significant role for Smad4 in promoting genomic stability through regulation of the Fanconi anemia/BRCA DNA repair pathway [10]. Despite these observations, precisely how the TGF- $\beta$ 
pathway contributes to toxin-induced DNA damage repair remains unclear.

Previous studies indicate that $\beta 2$ SP is a key TGF- $\beta$ / Smad3/4 adaptor and transcriptional cofactor that can regulate TGF- $\beta$ signaling and liver cancer development $[11,12]$. $\beta 2$-Spectrin is a dynamic intracellular nonpleckstrin homology $(\mathrm{PH})$-domain protein that belongs to a family of polypeptides implicated in cell polarity. Through associated binding partners, such as ankyrin, spectrins target and stabilize membrane proteins, such as ion transporters, exchangers, and cell adhesion molecules, in diverse tissues and cell types, including erythrocytes, gut, liver, and brain cells [13]. Spectrin dysfunction has previously been linked to abnormalities in mammalian physiology, including elliptocytosis, anemia, and cerebellar degeneration. More recently, spectrins have been linked to multiple signaling pathways, including cell cycle regulation, DNA repair, and TGF- $\beta$ signaling [11, 14, 15]. Sptbn1 heterozygous mice are robust genetic models of liver malignancies associated with loss of TGF- $\beta$ signaling, with more than $40 \%$ of mice spontaneously developing liver tumors [9, 12, 16-18]. Homozygous loss of Sptbn1 in mouse is embryonic lethal due to multiple abnormalities of the liver, gut, and brain, indicating an essential role in embryogenesis [11]. Here, we report that Sptbn1-null cells or cells deficient in $\beta 2 \mathrm{SP}$ display a marked defect in DNA damage repair by the homologous recombination (HR) pathway in response to various exogenous mutagens.

\section{RESULTS}

Homozygous Sptbn1 null (Sptbn $1^{-/-}$or $\beta 2 S P^{-/-}$) mice are embryonic lethal. Mutant embryos examined at E11.5 post coitus (p.c.) display a loss of TGF- $\beta$ signaling and a number of morphological abnormalities such as retarded growth, liver and gut hypoplasia, cardiac muscle hypertrophy, and neural defects [11]. Interestingly, a similar phenotype was described for double knockout Aldh2 $2^{-/} /$Fancd $^{-/-}$mice in a study demonstrating that the acetaldehyde-catabolizing enzyme aldehyde dehydrogenase 2 (Aldh2) is essential for embryonic viability of mice deficient in the Fanconi anemia complementation group D2 (Fancd2) DNA repair gene [1]. Since Aldh2 $2^{-/} /$Fancd $^{-/-}$mice are remarkably sensitive to ethanol exposure, both in utero and postnatally, we asked whether cells deficient for $\beta 2 \mathrm{SP}$ are sensitive to DNA damaging agents.

\section{B2SP depletion exhibits spontaneous genomic instability}

We examined first whether $\beta 2$ SP-deficient cells exhibit spontaneous genomic instability by measuring chromosomal aberrations at metaphase in Sptbn $1^{-/}$and
Sptbn $1^{+/+}$MEFs. Sptbn 1-/ MEFs had a significantly higher frequency of chromosomal aberrations of various types (fragments, radials and translocations like Robertsonian mutations) than wild-type MEFs (Figures 1A-1E). Furthermore, when SPTBN1 was depleted by specific siRNA in human cells (Figure 1F), a subsequent higher frequency of fragments, radials and dicentrics was observed (Figures 1G-1I). To determine whether telomere stability is affected by $\beta 2$ SP depletion, fluorescent in situ hybridization using telomere and centromere specific probes was used as described previous [19, 20]. Human $\beta 2 \mathrm{SP}$ deficient cells showed frequent loss of telomeres, which could result in telomere fusions that produce dicentrics, which were seen at a frequency similar to the translocations seen in mouse cells.

\section{Role of $\beta 2 \mathrm{SP}$ in cell survival after exposure to genotoxic agents}

We measured cell survival by assays described previously [21-24] and observed that exponentially growing Sptbn $1^{-/-}$MEFs and $\beta 2$ SP depleted human cells had a modest but statistically significant reduction in survival post irradiation as compared to the respective control cells (Figures 2A, 2B). Similarly, Sptbn $1^{-/-}$MEFs as well as $\beta 2 \mathrm{SP}$ depleted human cells were much more sensitive to hydroxyurea (HU) induced replication stress than control cells (Figures 2C, 2D). Since we observed that depletion of $\beta 2 \mathrm{SP}$ in mouse and human cells had similar effects on IR or HU induced cell killing, we then examined cell survival after treatment with formaldehyde, camptothecin, mitomycin $\mathrm{C}$ and cisplatin but only in MEFs (Figures 2E-2H) [25]. Sptbn $1^{-/-}$MEFs were more sensitive to intra- and interstrand cross-linking agents like formaldehyde, mitomycin C (MMC) and cisplatin as well as the topoisomerase inhibitor like camptothecin (Figures 2E-2H). All these agents reduced cell survival in Sptbn $1^{1^{-1}}$ MEFs as compared to Sptbn $1^{+/+}$MEFs, suggesting a role for $\beta 2 \mathrm{SP}$ in cell survival following exposure to genotoxic agents. Since cell killing usually correlates with defective DNA damage repair, we determined whether the reduced cell survival observed in $\beta 2$ SP depleted cells was the result of impaired DNA damage repair.

\section{B2SP-deficiency impairs DNA damage response}

One of the earliest detectable steps in the recruitment of repair factors to sites of DNA damage, particularly IR-induced DNA double-stranded breaks (DSBs), is phosphorylation of H2AX on serine 139 $(\gamma-\mathrm{H} 2 \mathrm{AX})$, which is linked to the activation of most DNA repair pathways [26-29]. Therefore, we initiallyasked if the IR-induced $\gamma$-H2AX response was perturbed by $\beta 2 S P$ depletion. Upon exposure to IR, we found that $\gamma-\mathrm{H} 2 \mathrm{AX}$ was equivalently detectable by $10 \mathrm{~min}$ in both 
of Sptbn $1^{-/-}$and Sptbn $1^{+/+}$MEFs (Figure 3A). However, Sptbn $1^{-/}$cells had markedly higher levels of residual $\gamma-\mathrm{H} 2 \mathrm{AX}$ at later time points, suggesting abbreviated DNA damage processing compared to that of Sptbn $1^{+/+}$ MEFs (Figure 3A). This phenotype was recapitulated in human cells with $\beta 2$ SP depletion after 2 Gy IR exposure (data not shown). The initial appearance of 53BP1 foci (Figure 3B) in Sptbn $1^{-/-}$and Sptbn $1^{+/+}$MEFs was also similar, however there was higher residual 53BP1 foci in Sptbn $1^{-/-}$MEFs as compared to Sptbn $1^{+/+}$MEFs indicating defective recruitment of other factors involved in DNA damage repair. A higher level of residual 53BP1

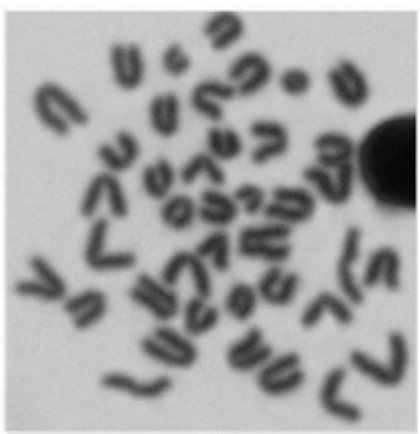

(A)

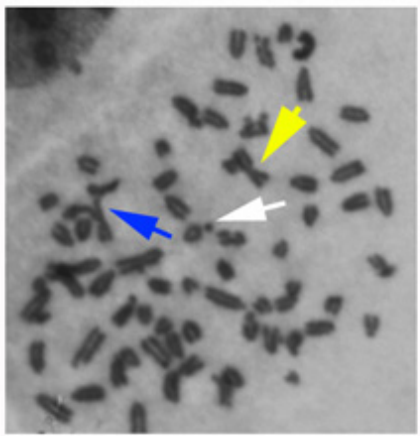

(C)

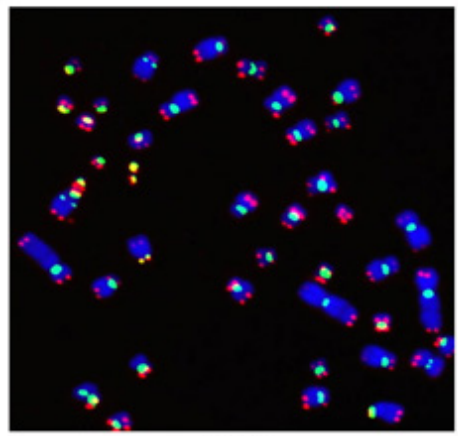

(G)

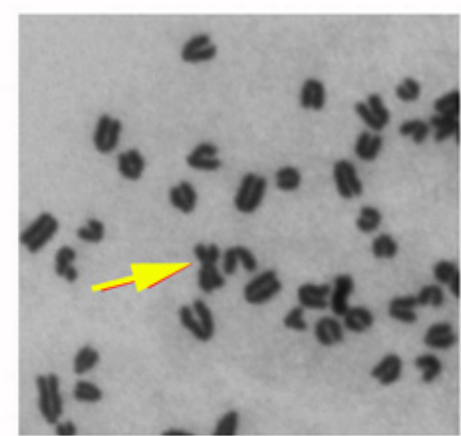

(B)

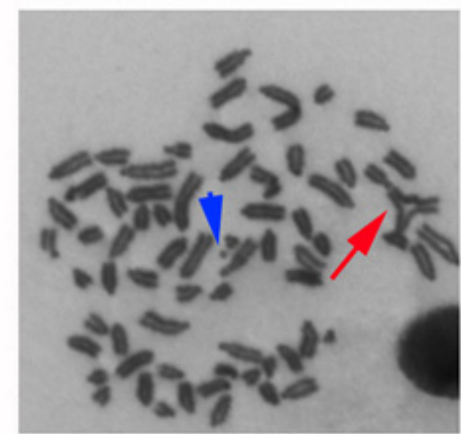

(D)

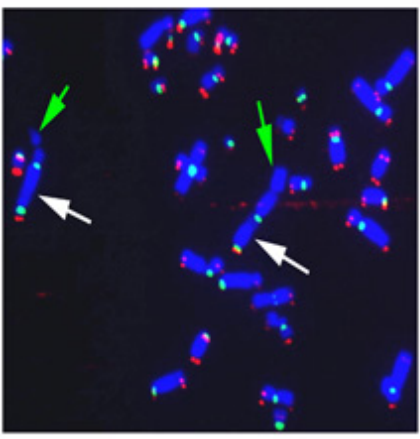

(H)
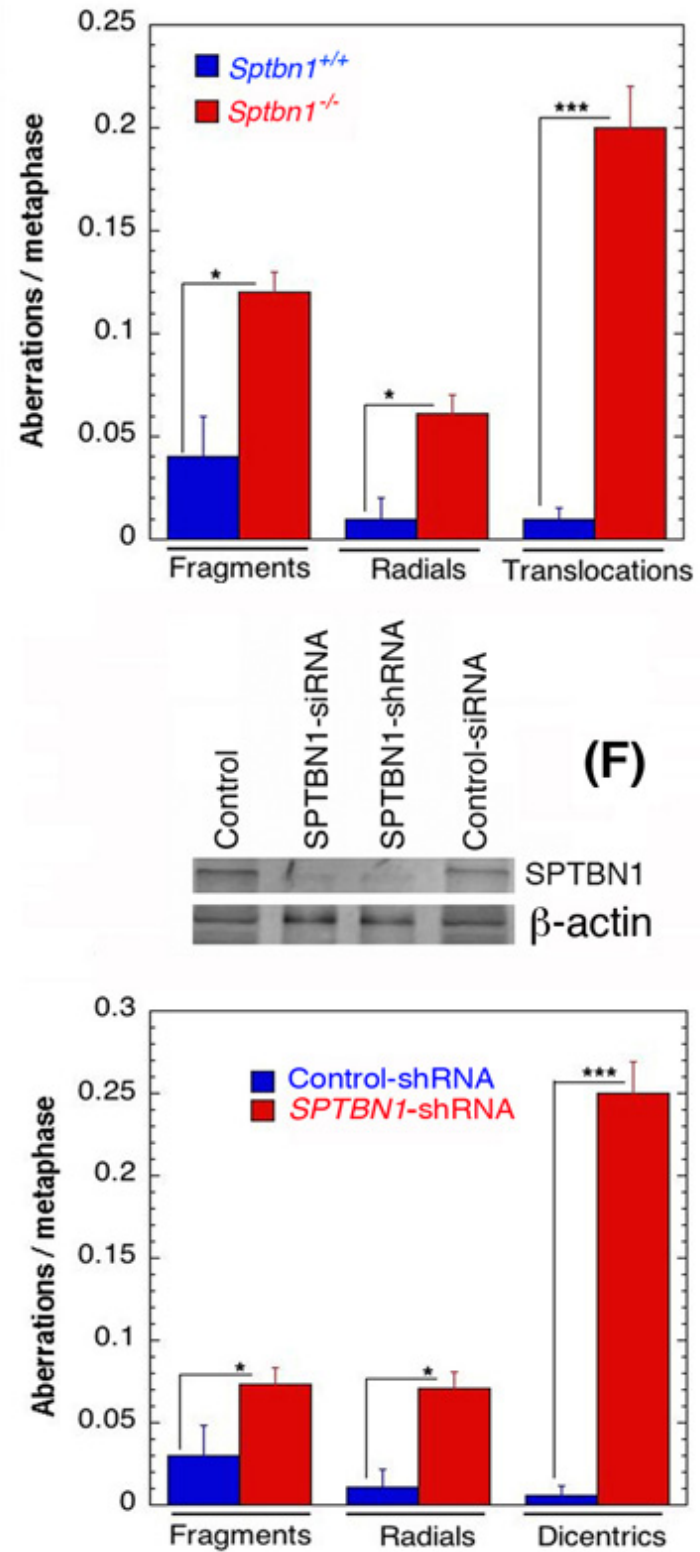

(E)

(I)

Figure 1: Spontaneous genomic instability after $\beta 2 S P$ depletion in mouse embryonic fibroblasts $\left(\right.$ Sptbn $\left.1^{--}\right)$and human cells. A., B. Metaphases from wild type Sptbn1 $1^{+/+}$MEFs. A. Metaphase with normal telocentric chromosomes and B. metaphase with one metacentric chromosomes like robertsonian mutation indicated by arrow. C., D. Metaphases from mutant Sptbn1 $1^{-/-}$MEFs. C. Metaphase showing robertsonian mutation indicated by (yellow arrow), fragment indicated by white arrow and end association indicated by blue arrow. D. Metaphase showing radial indicated by red arrow and fragment with blue arrow. E. Comparison of different types of chromosome

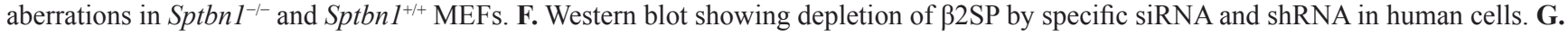
Human metaphase chromosomes showing centromeres (green) and loss of telomeres (red) signals detected by FISH using specific probes. H. Metaphase from $\beta 2$ SP depleted cells showing dicentrics indicated by white arrow and telomere signals indicated by green arrow. I. Comparison of different types of aberrations seen in cells with and without depletion of $\beta 2$ SP. Quantification of aberrations from 300 metaphase spreads of three independent experiments. ${ }^{*} p<0.05$; ** $p<0.01$; *** $p<0.001$ as determined by Student $t$ - test. 


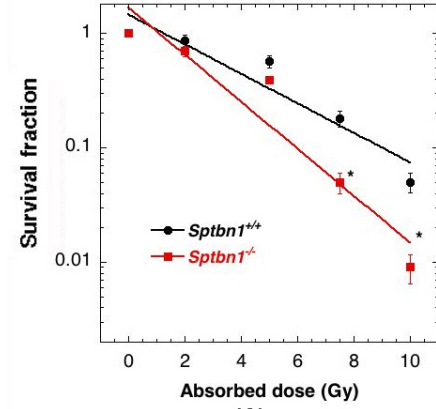

(A)

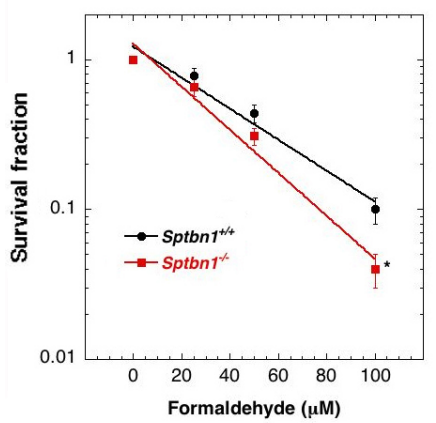

(E)

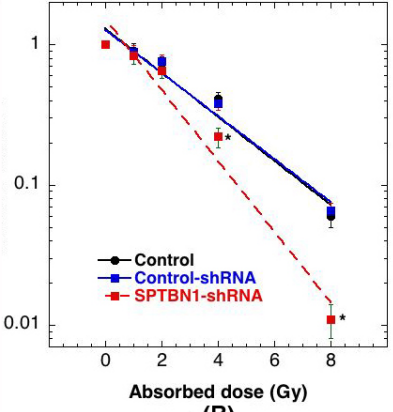

(B)

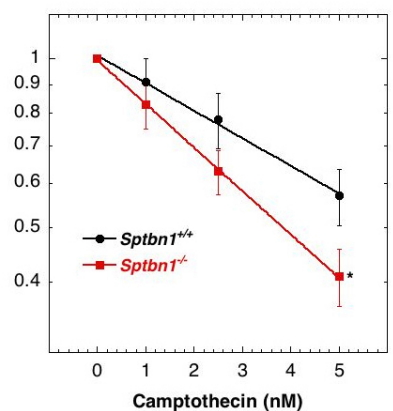

(F)

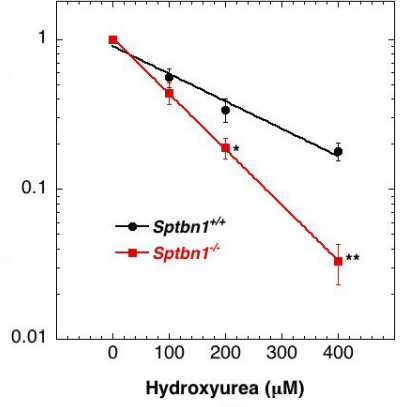

(C)

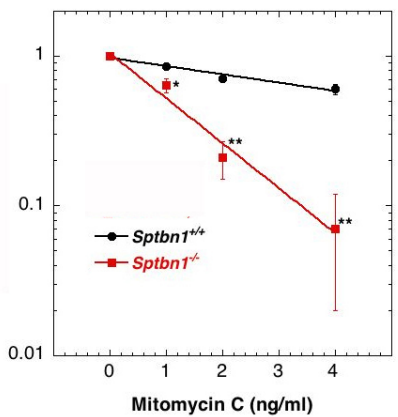

(G)

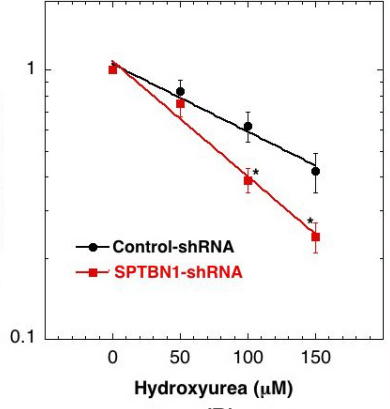

(D)

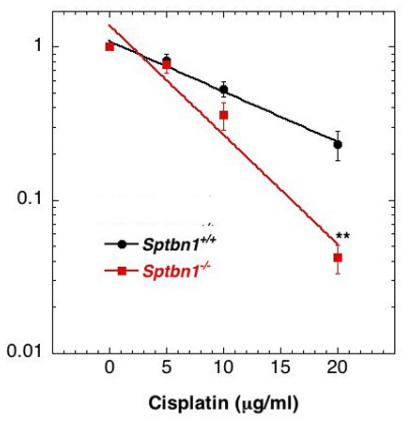

(H)

Figure 2: Cells depleted for $\beta 2 S P$ have reduced cell survival after exposure to different genotoxic agents. A. MEFs exposed to graded doses of IR at the dose rate of 1 Gy per min; B. Human cells with and without depletion of $\beta 2$ SP exposed to IR; C. MEFs treated with hydroxyurea; D. Human cells with and without depletion of $\beta 2 S P$ treated with hydroxyurea; E. MEFs treated with formaldehyde; F. MEFs treated with camptothecin; G. MEFs treated with mitomycin C and $\mathbf{H}$. MEFs treated with cisplatin.

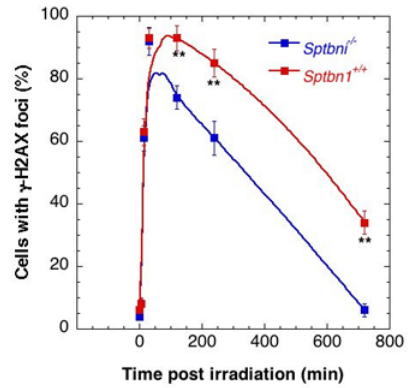

(A)

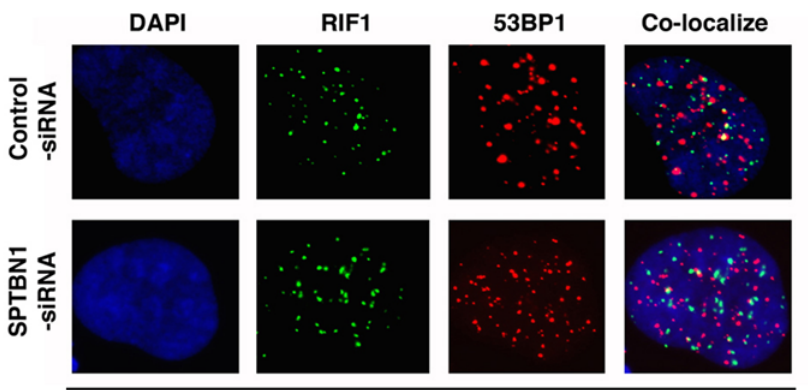

(E)

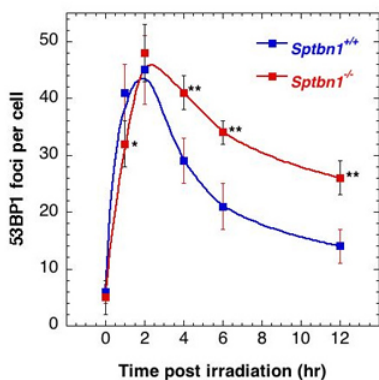

(B)

Co-localize

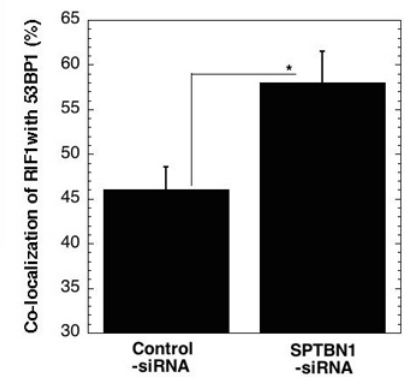

(F)

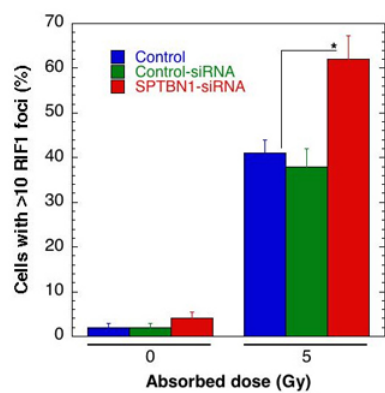

(D)

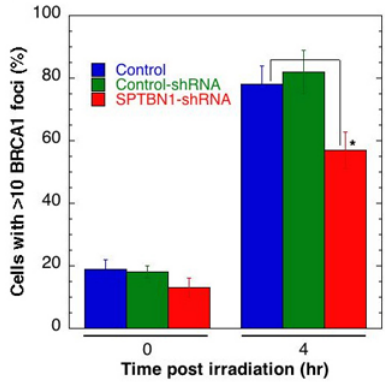

(G)

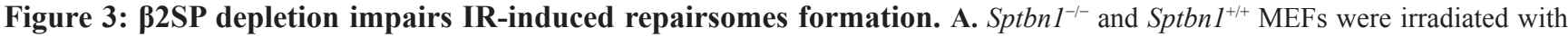

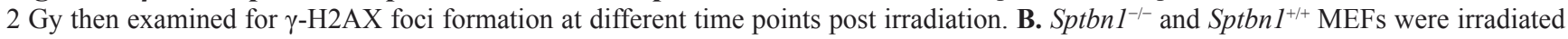
with 4 Gy examined for 53BP1 foci at different time points post irradiation. C. Quantification of human cells with 53BP1 foci, with and without $\beta 2$ SP depletion, 4 hour after exposure to 5 Gy. D. Quantification of human cells with RIFI foci, with and without $\beta 2$ SP depletion 4 hour after exposure to $5 \mathrm{~Gy}$. E. Colocalization of RIF1 and 53BP1 foci in human cells with and without $\beta 2$ SP depletion. F. Quantification of colocalization of RIF1 and 53BP1 foci. G. Error bars represent standard deviations, 3 independent experiments were performed. ${ }^{*} p<$ 0.05 and ${ }^{*} p<0.01$ Student $t$-test. 
foci was also seen in $\beta 2$ SP depleted human cells (Figure $3 \mathrm{C})$, supporting the argument that the effect of $\beta 2 \mathrm{SP}$ on the DNA damage response is conserved in human and mouse cells. Since 53BP1 protein has been implicated in the regulation of DNA DSB pathway choice [30-32], and the first effector of 53BP1 is RIF1 [32-37], we compared the kinetics of IR-induced RIF1 foci appearance and

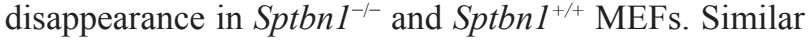
to 53BP1 status in $\beta 2 \mathrm{SP}$ depleted cells, higher residual RIF1 foci were observed in Sptbn $1^{-/-}$MEFs as compared to Sptbn $1^{+/+}$MEFs, suggesting further that recruitment of repair associated proteins is effected by $\beta 2 \mathrm{SP}$ depletion (Figure 3C, 3D). Sptbn $1^{-/-}$MEFs also have a higher frequency of co-localized 53BP1 and RIF1 foci as

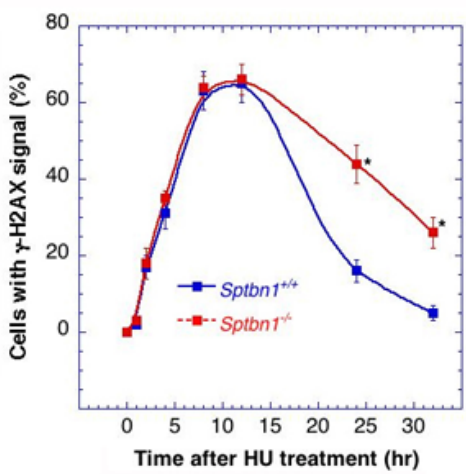

(A)

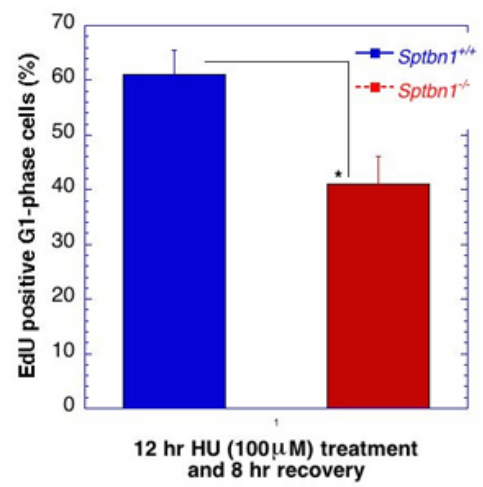

(D)

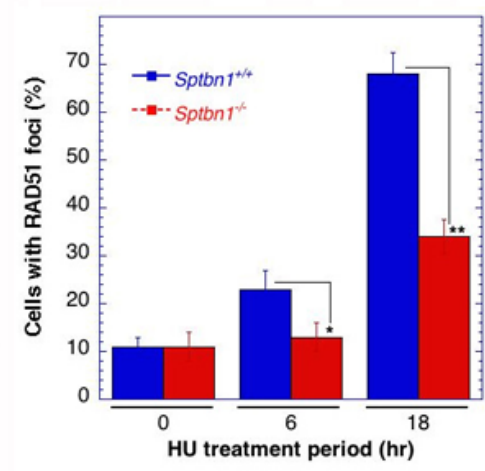

(G)

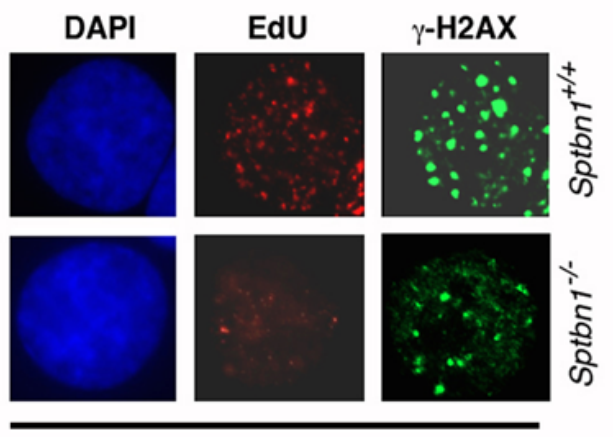

(B)

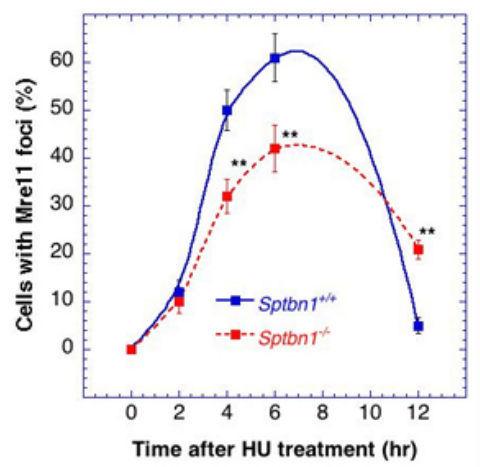

(E)

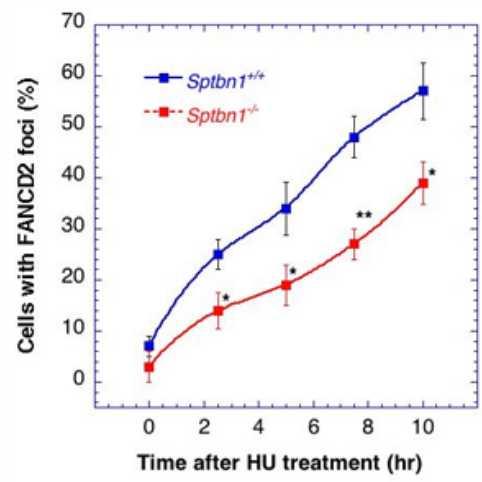

(H)

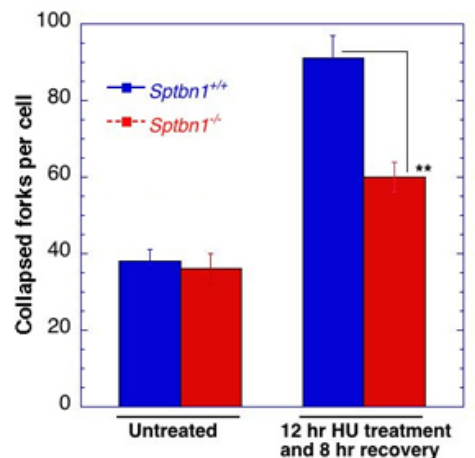

(C)

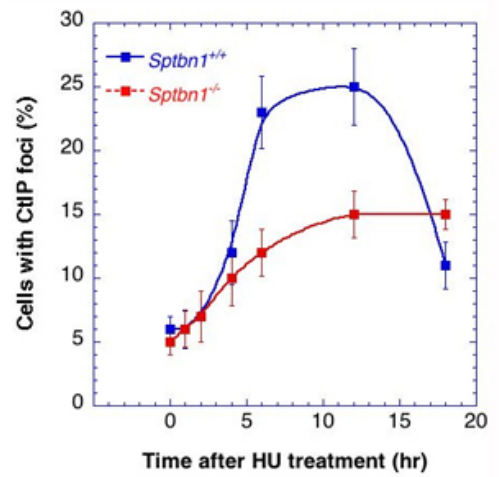

(F)

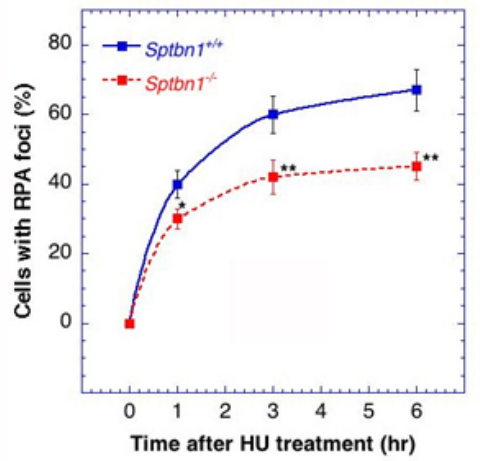

(I)

Figure 4: Comparison of Sptbn $1^{-/-}$and Sptbn $1^{+/+}$MEFs for DNA damage response after hydroxyurea treatment. A. Quantification of cells with $\gamma$-H2AX foci. B. Cells stained for DNA with DAPI and $\gamma$-H2AX immunostaining. EdU-positive S/G2 cells (selected by DAPI staining) were selected only for $\gamma-\mathrm{H} 2 \mathrm{AX}$ focus counting. C. The number of larger $\gamma-\mathrm{H} 2 \mathrm{AX}$ foci counted in late S/G2phase cells, representing collapsed forks. The quantification of EdU-positive late S/G2-phase cells was performed as described previously [25]. D. Histogram showing percent EdU-positive G1 phase cells. A total of 3,000 cells were counted, and the means from three experiments are plotted. E.-I. Frequency of cells with Mre11 foci E., CtIP foci F., RAD51 foci G., FANCD2 foci H. and RPA foci I.. ${ }^{*} p<0.05$ and ${ }^{*} p$ $<0.01$, Student $t$-test. 
compared to Sptbn $1^{+/+}$MEFs (Figures 3E, 3F). Since the 53BP1-interacting protein RIF1 is critical for inhibition of DNA end resection in BRCA1-deficient cells [38], we compared IR-induced BRCA1 foci formation in Sptbn $1^{-1-}$ and Sptbn $1^{+/+}$MEFs and observed that $\beta 2$ SP loss reduced BRCA1 foci (Figure $3 \mathrm{G}$ ), suggesting that $\beta 2 \mathrm{SP}$ promote recruitment of the resection machinery involved in HRdependent repair.

Hydroxyurea treatment induces replicative stress and when exponential-phase cells with and without $\beta 2$ SP depletion were treated with the drug, a significant decrease in the disappearance kinetics of $\gamma-\mathrm{H} 2 \mathrm{AX}$ foci was detected (Figure 4A) [39] as well as a reduced number of large $\gamma-\mathrm{H} 2 \mathrm{AX}$ foci (Figure 4B), which are an indication of collapsed replication forks (Figure 4C). Delayed cell cycle progression was also observed as the frequency of G1 phase cells was significantly lower in cells depleted for $\beta 2 \mathrm{SP}$ (Figure 4D). Consistent with the abnormally sized $\gamma$-H2AX foci, a significant reduction in Mre11, CtIP, RAD51, FNACD2 and RPA foci formation was observed in hydroxyurea treated $\beta 2 \mathrm{SP}$-deficient cells (Figures 4E-4I), Thus, the survival results, the defective disappearance kinetics of $\gamma-\mathrm{H} 2 \mathrm{AX}$ foci and the reduced number of MRE11, CtIP, RAD51, FNACD2, and RPA foci after hydroxyurea treatment, all suggest that DNA damage repair is impaired in $\beta 2 \mathrm{SP}$ deficient cells and that $\beta 2 \mathrm{SP}$ may have a specific role in homologous recombination repair.

\section{Role of $\beta 2 S P$ in S-phase specific chromosome damage repair}

Cells depleted for $\beta 2 \mathrm{SP}$ have higher residual $\gamma$-H2AX and 53BP1 foci, and lower Rad51 and BRCA1 foci, indicating defective repair of DNA DSBs by the HR pathway, the repair pathway most commonly up regulated in S-phase cells. In addition, we found that Sptbn1 $1^{-/}$ MEFs have a higher frequency of 53BP1 and RIF1 foci co-localization than in Sptbn $1^{+/+}$MEFs even after $12 \mathrm{hr}$ of HU treatment, suggesting that HR repair protein loading at DNA damage sites is impaired, an observation further supported by the reduced frequency of $\operatorname{Rad} 51, \mathrm{BRAC} 1$ foci in post treatment Sptbn $1^{-/-}$MEFs. To examine the cell cycle stage specific repair of IR-induced DNA damage, we examined chromosome aberrations produced at different phases of the cell cycle and detected in metaphase cells as described previously [20, 40, 41].

Cell cycle phase-specific chromosome aberrations were ascertained based on the frequency of chromosomal and chromatid-type aberrations observed at metaphase. G1-specific aberrations detected at metaphase are mostly of the chromosomal type and include a high frequency of dicentrics (Figures 5A, 5B) [42]. S-phase-type aberrations detected at metaphase are chromosomal, as well as those involving chromatids (Figure 5C). G2-type aberrations detected at metaphase are predominantly the chromatid type with the least number of dicentrics (Figure 5D). To determine G1-type chromosome damage, cells were treated with 3 Gy of IR and aberrations were scored at metaphase as previously described [40, 42]. No differences in residual IR-induced G1 chromosomal aberrations were detected in metaphase cells with or without $\beta 2$ SP depletion (Figure 5E). To determine whether defective repair can be documented in cells depleted for $\beta 2 \mathrm{SP}$ in other phases of the cell cycle other than G1, S-phase-specific chromosome aberrations were evaluated. Thus, cells were exposed with 2 Gy of IR and metaphases collected 4 to 6 $\mathrm{h}$ post irradiation. Cells depleted for $\beta 2 \mathrm{SP}$ collected post irradiation displayed higher frequencies of metaphases with chromatid and chromosomal aberrations than control cells (Figure 5F). In contrast, when cells were treated with 1 Gy of IR, depletion of $\beta 2$ SP had minimum effect on G2-phase-specific chromosome repair (Figure 5G). These observations suggest a role for $\beta 2 \mathrm{SP}$ in repairing chromosome damage in the $\mathrm{S}$ phase of the cell cycle, where HR is up-regulated.

\section{B2SP-deficient cells are defective in resolution of stalled DNA replication forks}

The disappearance of $\gamma-\mathrm{H} 2 \mathrm{AX}$ foci in $\beta 2 \mathrm{SP}$ deficient cells treated with $\mathrm{HU}$ was significantly delayed (Figure 4A) and they also had a reduced number of large $\gamma$-H2AX foci (Figure 4B) as compared to controls. Sptbn $1^{-/-}$cells treated with HU have a high frequency of collapsed forks (Figure 4C) and cell cycle progression is delayed as the frequency of G1 phase cells was significantly lower (Figure 4D). To determine the mechanism by which Sptbn1 deficiency impacts the resolution of stalled DNA replication forks after DNA repair, we compared the restart of stalled forks in cells with and without Sptbn1 using the DNA fiber technique [25, 43]. Mouse embryonic fibroblasts were pulse-labeled with 5-iododeoxyuridine (IdU), treated with $\mathrm{HU}$ for different time periods to deplete the nucleotide pool, and then washed and pulselabeled with 5-chlorodeoxyuridine (CldU) (Figures 6A, $6 \mathrm{~B})$ as described previously $[25,43]$. In growing cells continuously exposed to HU, we observed a higher percentage of stalled DNA replication forks (IdU signals) in mutant Sptbn $1^{-/-}$cells than in wild type Sptbn $1^{+/+}$cells after 4 hours of treatment (Figure 6C). Moreover, after removal of the HU block, we observed fewer contiguous IdU/CldU signals in Sptbn $1^{-/}$cells, indicating that the restart of previously initiated replication origins in the $\beta 2 \mathrm{SP}$ deficient cells was decreased as compared to control cells, which readily resumed DNA synthesis (Figure 6D). The deficiency of $\beta 2 \mathrm{SP}$ appeared to decrease fork speed as $S p t b n 1^{-/}$MEFs had a relatively low frequency of fibers with large labeled fork fragments as compared to $S p t b n 1^{+/+}$ MEFs (Figure 6E). 


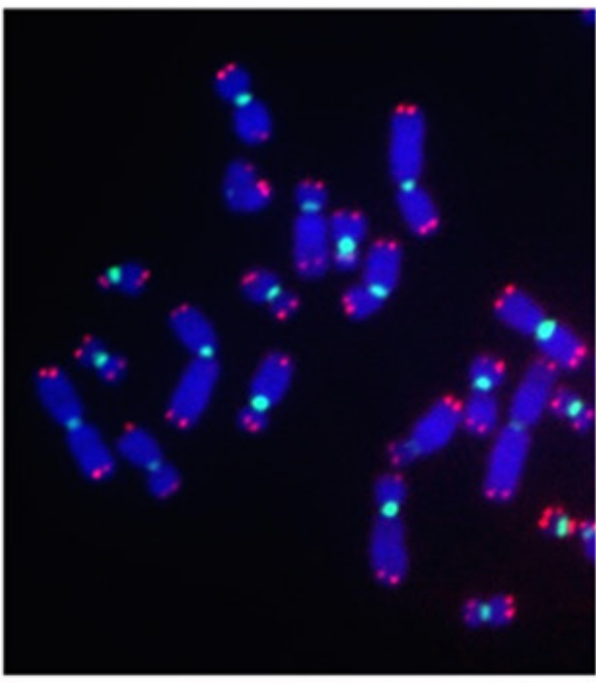

(A)

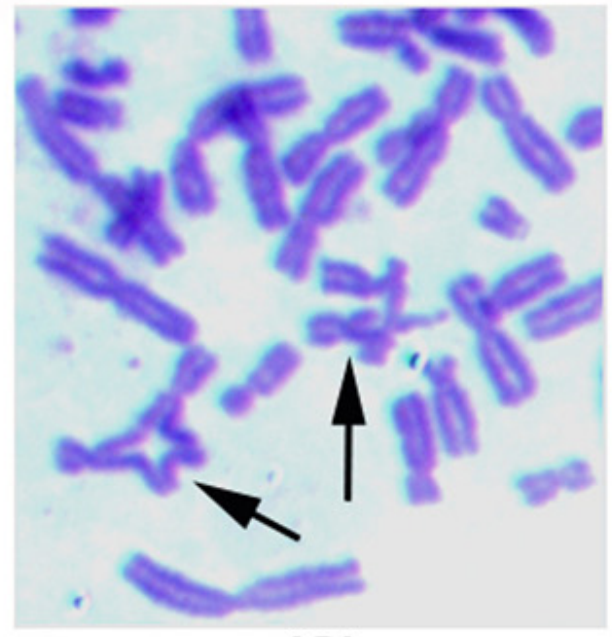

(C)

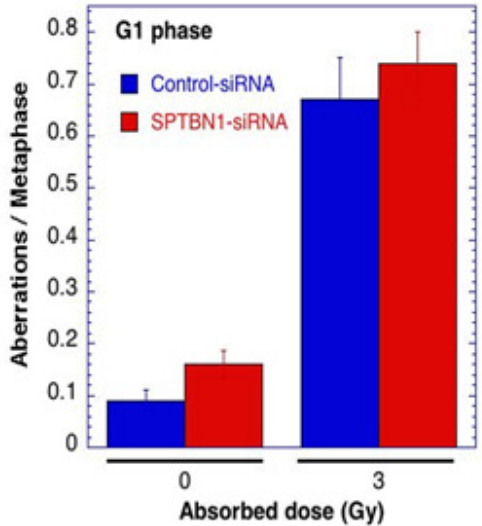

(E)

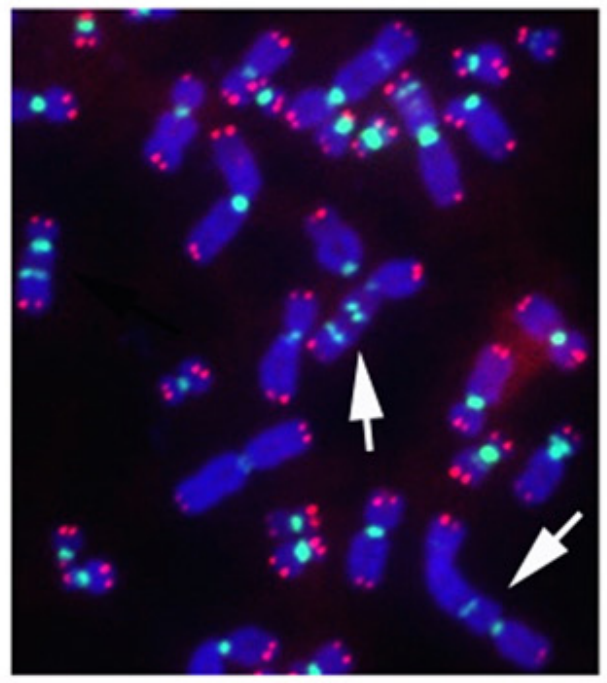

(B)

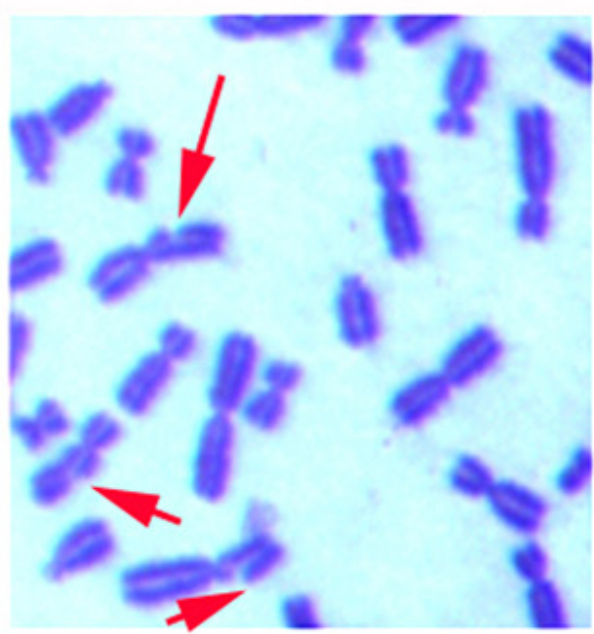

(D)

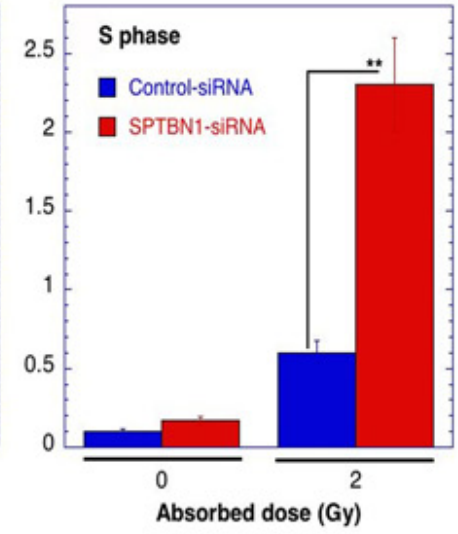

(F)

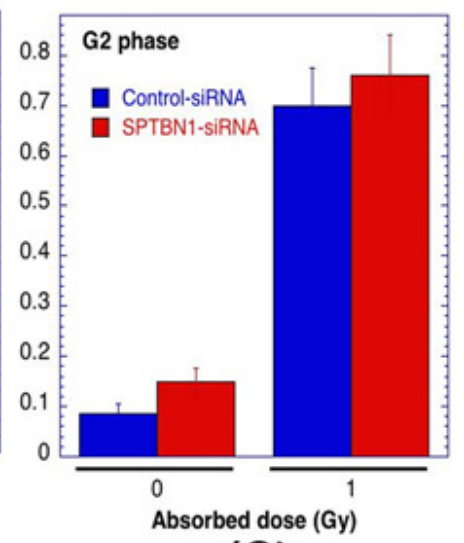

(G)

Figure 5: Cells deficient for $\boldsymbol{\beta 2 S P}$ show defective S-phase specific chromosome repair. Cell cycle phase specific chromosomal aberrations induced by IR in human cells. A., B. Metaphases of human cells showing centromeres green and telomeres red detected by FISH as described previously [19, 20,63]. Metaphase chromosomes from control A. and G1-type metaphase chromosomes, arrows indicate dicentrics B.. C.,D. S- and G2-type chromosome aberrations detected by Giemsa staining as described previously [64, 65], S-phase C. showing radials indicated by black arrow C. and G2-phase D. showing breaks and gaps indicated by red arrows. E.-G. Quantification of chromosomal aberrations: G1-phase type E., S-phase type F. and G2-phase type G.. ${ }^{* *} p<0.01$, Student $t$-test. 


\section{B2SP depletion affects DNA resection}

A resection assay was used to quantitate ssDNA at DSBs, induced in human cells by AsiSI endonuclease in the presence and absence of $\beta 2$ SP. The AsiSI enzyme, fused to the estrogen receptor hormone-binding domain, translocates to the nucleus following 4-OHT treatment to generate sequence-specific DSBs (5'-GCGATCGC-3') [45]. To measure resection adjacent to specific DSBs, a AsiSI site known to be cleaved with high efficiency on Chromosome 1 (DSB1, Chr 1: 88992915 [GRCh38/ hg38]) was examined. Three pairs of qPCR primers were used that amplify across BsrGI restriction sites at various distances from each AsiSI site [46]. The percentage DSBs resected was measured by ( $\%$ ssDNA) / ( $\%$ DSB $)$ at the sites after $4 \mathrm{hr}$ of $4-\mathrm{OHT}$ treatment. Depletion of $\beta 2 \mathrm{SP}$ decreased resection both immediately adjacent to the DSB site as well as further downstream of the site (Figure 7A). This result was similar to that observed in MRE11 depleted cells, a factor known to be required for DNA end resection during HR repair.

The frequency of RIF1 colocalization with 53BP1 is significantly higher in post irradiated human $\beta 2 \mathrm{SP}$ depleted cells than in control cells. Consistent with results that $\beta 2 \mathrm{SP}$ has a role in HR, there was a reduced frequency of cells with IR-induced BRCA1, CtIP, RAD51, RPA2, MRE11, RAP80, and FANCD2 foci in $\beta 2$ SP depleted cells, supporting a direct link to DSB repair by HR. To further examine the role of $\beta 2 \mathrm{SP}$ in DNA repair protein recruitment upon DSB induction, we determined the levels of RAD51, MRE11 and KU80 at the DSB site before and after DSB induction in cells with and without $\beta 2$ SP

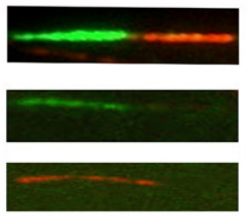

ongoing replication

stalled fork

newly initiated fork

(A)
- Hydroxyurea
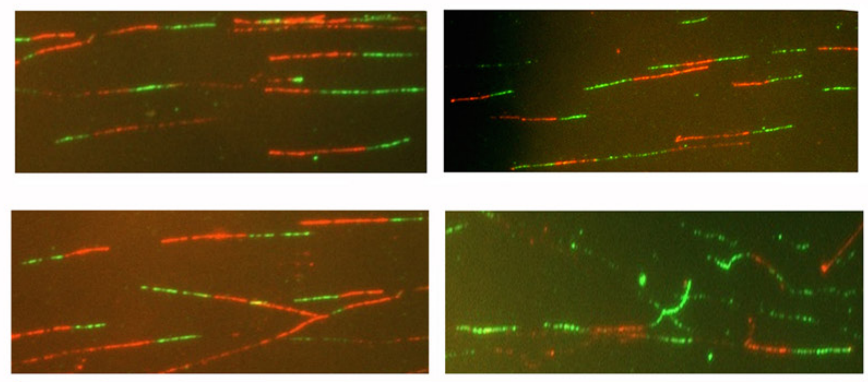

(B)

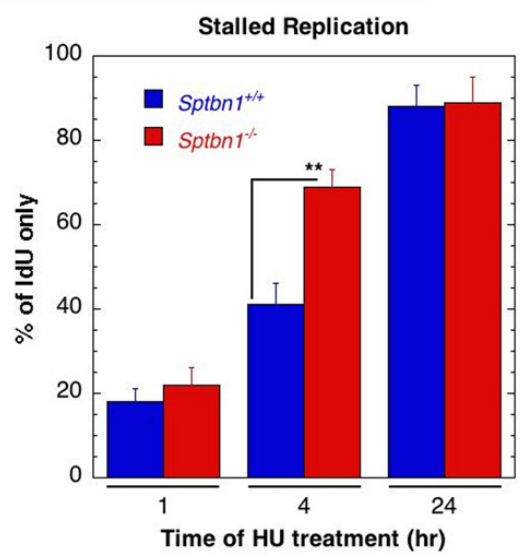

(C)

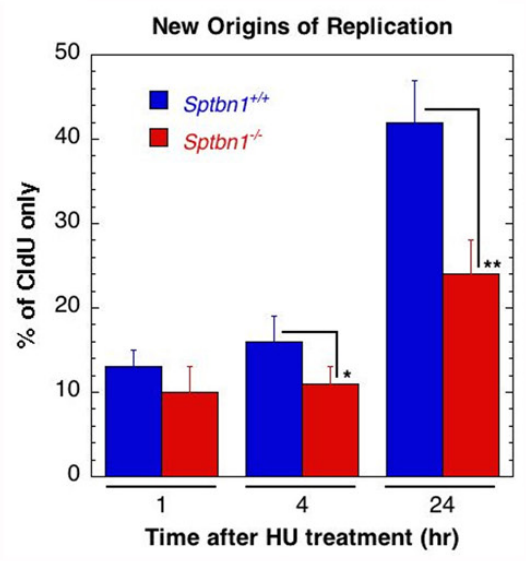

(D)

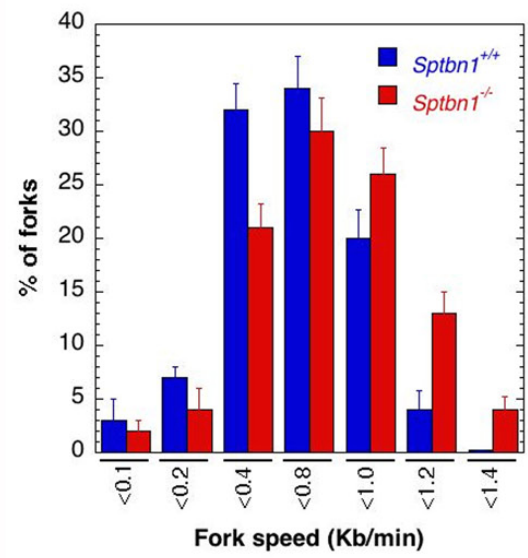

(E)

Figure 6: Sptbn 1 ${ }^{-/}$MEFs exhibit defective stalled DNA replication fork resolution and new origins of replication. A.,

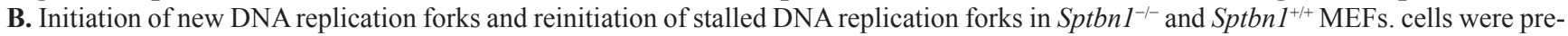
labeled with 5-iododeoxyuridine (IdU), treated with hydroxyurea (HU) for the indicated intervals, and then rinsed to remove HU followed by post labeling with 5-chlorodeoxyuridine (CldU) (upper panel) as described previously [66]. The cells were fixed and immunostained with IdU (green) and CldU (red) antibodies. A. Three major types of labeled DNA tracts for analysis are shown. B. Sptbn1 $1^{+/+}$and Sptbn1 $1^{-/}$ MEFs with and without treatment of hydroxyurea. C. Percentages of stalled DNA replication forks (IdU only signals) in $S p t b n 1^{-/-}$and $S p t b n 1^{+/+}$cells after HU treatment. D. New origins (CldU signals) in Sptbn $1^{-1-}$ and Sptbn $1^{+/+}$cells. E. Percentage of forks with fork speed in Sptbn $1^{-/}$and Sptbn $1^{+/+}$MEFs. Means \pm standard deviations of 3 independent experiments are shown in. ${ }^{*} p<0.05$; ** $p<0.01$, Student $t$-test. 
depletion (Figure 7B). We compared the levels of RAD51, MRE11 and KU80 at different distances from an I-SceI induced DSB site using ChIP analysis with site specific primers [47]. The HR related proteins Rad51 and MRE11 accumulated at the I-SceI induced DSB site to relatively lower levels in $\beta 2$ SP depleted cells, where as KU80 levels were increased by depletion (Figure $7 \mathrm{C}$ ). Since $\beta 2 \mathrm{SP}$ depletion reduces the formation of IR-induced RAD51 foci and RAD51 localization at a defined DSB site, a hallmark of HR $[27,48]$, we examined individually the effect of $\beta 2$ SP depletion on non-homologous end joining (NHEJ) and HR based I-SceI induced DSB repair.

\section{B2SP depletion affects DNA DSB repair by homologous recombination}

Depletion of $\beta 2 S P$ affects both the DNA resection process as well as recruitment of DNA repair proteins, therefore, we assessed the impact of $\beta 2$ SP-deficiency on the two key DNA damage repair pathways: HR and NHEJ. We exploited in vivo reporter systems for either HR or NHEJ in order to study the impact of $\beta 2 \mathrm{SP}$ knockdowns on DSB repair [23, 44] by using engineered cell lines that express a fluorescent protein only upon repair of I-SceI induced DSBs by the appropriate pathway $[23,33,48]$. Equivalent repair of the NHEJ-dependent fluorescent protein gene template was observed in cells with and without depletion of $\beta 2 \mathrm{SP}$ (Figure 7D), further confirming that $\beta 2 \mathrm{SP}$ is not required for DSB repair by the NHEJ pathway. This is also consistent with the normal

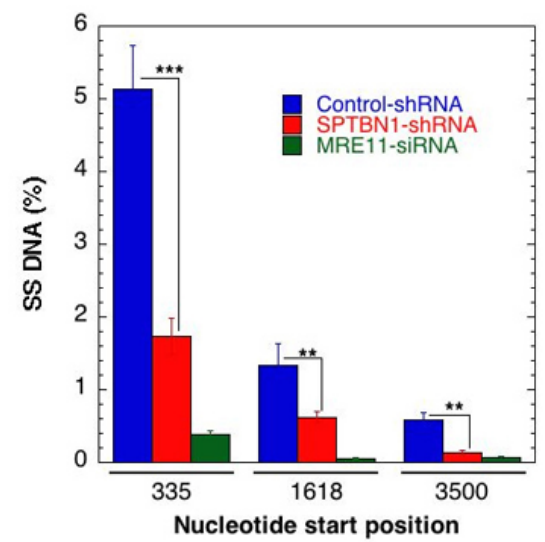

(A)

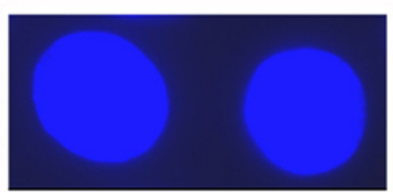

- I-Scel

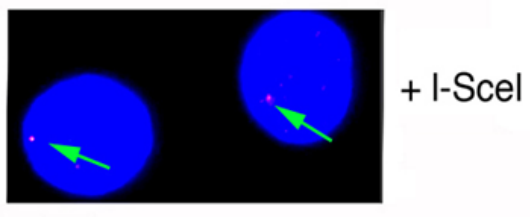

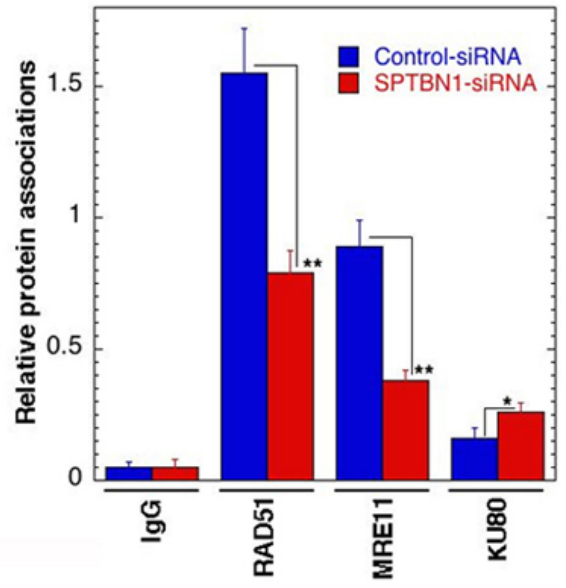

(C)
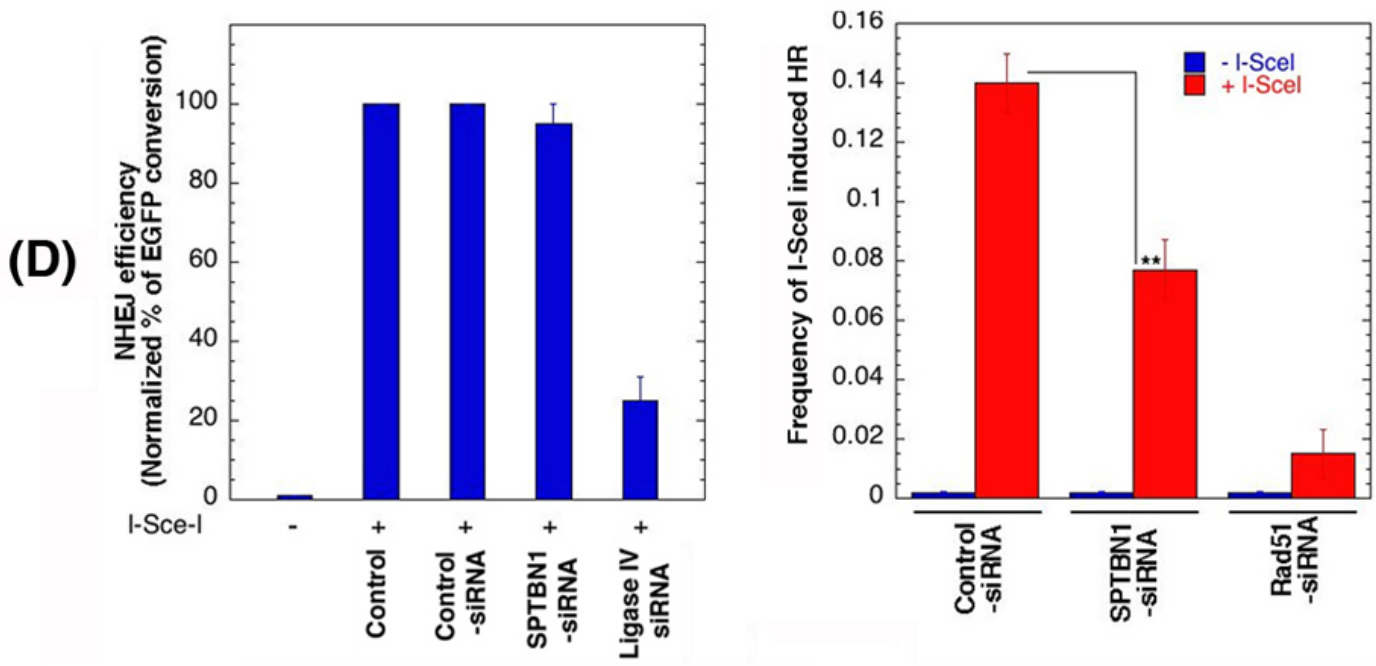

(E)

Figure 7: $\beta 2 S P$ depletion affects DNA resection and DSB repair by homologous recombination. A. Quantification of single strand DNA (ssDNA) in cells with and without depletion of $\beta 2$ SP. B. Detection of I-SceI induced DSB by $\gamma$-H2AX immunostaining. Note arrow indicates the site of $\gamma-\mathrm{H} 2 \mathrm{AX}$ foci in cells expressing I-SceI. C. Detection of repair proteins at l-Scel sites by ChIP using the respective antibodies. D. Non-homologous end joining frequencies in human cells are shown after I-SceI induction in cells with and without depletion of $\beta 2$ SP. E. HR frequencies in human cells are shown with and without I-SceI induction. $* * p<0.01$, Student $t$-test. 
chromosomal damage repair observed in $\beta 2 \mathrm{SP}$ depleted G1 phase cells. The reconstitution frequency of a GFP HR reporter gene within a chromosomally integrated plasmid substrate $[20,49]$ was used to measure the dependence of HR on $\beta 2 S P$. In cells depleted of $\beta 2 S P$, the HR repair was defective as the number of GFP-positive cells was significantly decreased as compared to control (Figure 7E). These data suggest that $\beta 2$ SP is required for DNA DSB repair by the HR pathway but not by NHEJ. Overall, these results indicate that $\beta 2 \mathrm{SP}$ loss results in DNA damage repair defects at the level of stalled replication fork resolution and $\mathrm{HR}$, leading to chromosome aberrations in an S-phase specific manner.

\section{DISCUSSION}

SPTBN1 has emerged as a potent regulator of tumorigenesis as mice haploinsufficient for $\beta 2 \mathrm{SP}$ $\left(\right.$ Sptbn $\left.1^{+-}\right)$spontaneously develop hepatocellular carcinoma HCC [12]. Our study now uncovers a novel role for $\beta 2 \mathrm{SP}$ in DNA damage repair and maintenance of genomic stability. Thus, $\beta 2 \mathrm{SP}$ signaling is pivotal not only for regulation of hepatocyte proliferation and extracellular matrix deposition in the liver, as previously reported [50-53], but also for maintenance of genomic stability in the context of toxin-induced DNA damage. Indeed, TGF- $\beta$ is activated in response to tissue damage [54]. Interestingly, only double knockout Fancd2/Aldh2 mice display fetal alcohol syndrome (FAS), indicating that elevated genotoxic acetaldehyde was required for the FAS phenotype. When there is a deficiency of $\beta 2 S P$, it is possible that the TGF- $\beta$ pathway has additional sensitizing effects, thus rendering the mice more susceptible to DNA damage. For instance, TGF- $\beta$ plays a role in the reciprocal up-regulation of TLR4 signaling [55].

It is well established that 53BP1 enhances DSB repair through the error-prone NHEJ pathway by blocking the recruitment of resection proteins associated with HR repair $[38,56,57]$. In our analysis, cells with $\beta 2 \mathrm{SP}$ depletion had higher levels of residual 53BP1 foci as well as increased co-localization of 53BP1 and RIF1 supporting the argument $\beta 2 \mathrm{SP}$ plays a critical role in regulating the DNA DSB repair, specifically by the HR pathway. In addition DNA replication fork stalling and reduced initiation of new DNA replication forks are the likely underlying mechanistic basis for defective DNA interstrand cross-link repair observed in Sptbn1-deficient cells.

Recent studies by Zhi and coworkers also demonstrated that Sptbn 1 gene expression is positively correlated with E-cadherin and kallistatin expression in both HCV-associated HCC (Gene Expression Omnibus GSE6764) and hepatitis B virus (HBV)-associated HCC (Gene Expression Omnibus GSE14520) [58]. These data suggest that $\beta 2$ SP plays a tumor suppressive role through different signaling pathways in HCC. It is possible that the TGF- $\beta / \beta 2$ SP/SMAD3/FANCD2 axis may also be activated in response to virus-induced DNA damage and genomic instability, but this remains to be investigated further.

The present results validate recent discoveries that cytoskeletal proteins belonging to the spectrin/ankyrin family can regulate key signal transduction pathways by functioning as adaptor molecules [13]. Moreover, our results reinforce the concept that consideration of the role of these proteins in human physiology and disease may be pivotal for the development of new therapeutics acting through DNA damage repair pathways that aim to change the diseased state from injury to repair. The complex detoxifying function of the liver clearly exposes the organ to a phenomenal degree of genotoxic stress, which must be overcome in order to prevent DNA damage and the potential onset of liver cirrhosis and cancer. Our studies propose that in response to toxins, $\beta 2 \mathrm{SP}$ directly affects DNA repair to maintain genomic stability. Thus, characterizing the role of TGF- $\beta$ in alcohol-induced injury could potentially enhance our mechanistic insight into the basis for therapeutics targeting reactive aldehydes and DNA repair.

\section{MATERIALS AND METHODS}

\section{Cell culture, transfection and cell survival}

Human liver cancer cell line HepG2 (HB8065; ATCC, Rockville, MD) was cultured in DME/F12 medium (D5671; Sigma Aldrich, St Louis, MO) supplemented with 10\% fetal bovine serum (F2442; Sigma Aldrich). For transfection, Lipofectamine 2000 (Invitrogen, Carlsbad, CA) was used. shRNAs for $\beta 2 \mathrm{SP}$ (sc-36551-v) and shRNA control (sc-108080) were from Santa Cruz Biotechnology (Santa Cruz, CA), siRNAs were from Dharmacon (Lafayette, CO). For survival assay, three different assays were used: (a) regrowth curve, (b) microtiter well, and (c) clonogenic colony formation as described previously [21, 22]

\section{Immunostaining, foci measurements, NHEJ and HR assay}

Cells were grown in chamber slides, fixed in $2 \%$ paraformaldehyde for $15 \mathrm{~min}$, washed in phosphatebuffered saline (PBS), permeabilized for $5 \mathrm{~min}$ on ice in $0.2 \%$ Triton X-100, and blocked in PBS with $1 \%$ bovine serum albumin. The procedure used for immunostaining is the same as that described previously [33, 59, $60]$. Foci were counted by microscopic and imaging processes. Fluorescence images were captured by using epifluorescence microscope equipped with a chargecoupled device camera and software. Optical sections 
through nuclei were captured, and the images were obtained by projection of the individual sections. The results shown are from three independent experiments. Cells with a bubble like appearance or micronuclei were not considered for foci analysis. Antibodies used have been described previously $[25,33,61,62]$. The impact of $\beta 2 \mathrm{SP}$ on DNA DSB repair by NHEJ and HR was determined by using both IR- as well as I-Scel induced DNA DSB in fluorescent protein reconstitution assays. The impact of $\beta 2 \mathrm{SP}$ on repair protein recruitment to a defined I-SceI DSB was determined by ChIP and PCR. Induction of a site specific DSB was performed as described previously [23]. Commercial antibodies used have been described previously $[23,25,61,62]$

\section{DNA replication restart assay}

Mouse embryonic fibroblasts were pulse labeled with $50 \mu \mathrm{M}$ IdU for 20 minutes, washed 3 times with $1 \mathrm{X}$ PBS, treated with $2 \mathrm{mM}$ HU for the indicated intervals, washed 3 times with PBS to remove HU, and then incubated in fresh medium containing $50 \mu \mathrm{M}$ CldU for 20 minutes, and then washed 3 times with PBS. DNA fiber spreads were made using a modified procedure described previously [25]. Briefly, cells labeled with IdU and CldU were mixed with unlabeled cells in a ratio of $1: 10$, and 2 $\mu \mathrm{L}$ cell suspensions were dropped onto a glass slide and mixed with a $20 \mu \mathrm{L}$ hypotonic lysis solution for 8 minutes. Air-dried slides were fixed, and incubated with primary antibodies (rat monoclonal antibody anti-IdU [Abcam, Cambridge, MA] and mouse monoclonal antibody antiCldU [BD Biosciences, San Jose, CA]) and secondary antibodies (anti-rat Alexa Fluor 488- conjugated and antimouse Alexa Fluor 568-conjugated antibodies). Image J software was used to analyze the DNA fibers.

\section{Chromosomal aberration analysis}

For analysis of G1-phase-specific chromosome aberrations, cells were irradiated ( $3 \mathrm{~Gy}$ ), incubated for 10-12 hours, and then treated for 3 hours with colcemid, followed by hypotonic treatment and fixation for scoring metaphase chromosome aberrations [20]. Categories of asymmetric chromosome aberrations scored included Robertsonian fusions, dicentrics, centric rings, interstitial deletions, acentric fragments, rings, and terminal deletions [23]. For S-phase-specific chromosome aberrations, cells were irradiated ( 2 Gy) and incubated for 4-6 hours, and cells at metaphase were harvested after 3 hours of treatment with colcemid. S-phase-specific aberrations observed in the first round of cells at metaphase included triradials and quadriradials, breaks, and gaps [33]. For G2-type chromosome aberrations, exponential-phase cells were irradiated (1 Gy), incubated for 1 hour, and treated with colcemid for 3 hours, followed by hypotonic treatment fixation to analyze chromosome aberrations at metaphases [23]. The analysis of metaphase spreads to measure chromosomal aberrations was carried out as described previously [20, 23].

\section{Statistical analysis}

Differences between groups were evaluated using Student $t$ tests. Results are expressed as mean \pm standard deviation. For all statistical analyses, $p<0.05$ was considered statistically significant.

\section{ACKNOWLEDGMENTS}

We thank the members of Pandita laboratory at UTSW and HMRI for their support during the execution of present work. We thank Drs. Jian Chen and Lopa Mishra for providing reagents. This work was supported by funds from Houston Methodist Research Institute, MD Anderson Cancer Center, Houston, National Institute of Health grants CA129537, CA154320 and GM109768.

\section{CONFLICTS OF INTEREST}

No potential conflicts of interest were disclosed.

\section{Author contributions}

N.H., R.K. P., C.R.H., and T.K.P. designed research; N.H., R.K. P., K.M., S.H., D.S., A.M., S.C., V.C., and T.K.P. provided the intellect inputs, performed the experiment, reviewed data analyses; and N.H., R.K. P., K.M., C.R.H., and T.K.P. wrote the paper.

\section{REFERENCES}

1. Langevin F, Crossan GP, Rosado IV, Arends MJ and Patel KJ. Fancd 2 counteracts the toxic effects of naturally produced aldehydes in mice. Nature. 2011; 475:53-58.

2. Seitz HK and Stickel F. Molecular mechanisms of alcoholmediated carcinogenesis. Nat Rev Cancer. 2007; 7:599-612.

3. Moldovan GL and D'Andrea AD. To the rescue: the Fanconi anemia genome stability pathway salvages replication forks. Cancer Cell. 2012; 22:5-6.

4. Joo W, Xu G, Persky NS, Smogorzewska A, Rudge DG, Buzovetsky O, Elledge SJ and Pavletich NP. Structure of the FANCI-FANCD2 complex: insights into the Fanconi anemia DNA repair pathway. Science. 2011; 333:312-316.

5. Oberbeck N, Langevin F, King G, de Wind N, Crossan GP and Patel KJ. Maternal aldehyde elimination during pregnancy preserves the fetal genome. Mol Cell. 2014; 55:807-817.

6. Muraoka-Cook RS, Kurokawa H, Koh Y, Forbes JT, Roebuck LR, Barcellos-Hoff MH, Moody SE, Chodosh 
LA and Arteaga CL. Conditional overexpression of active transforming growth factor betal in vivo accelerates metastases of transgenic mammary tumors. Cancer Res. 2004; 64:9002-9011.

7. Kirshner J, Jobling MF, Pajares MJ, Ravani SA, Glick AB, Lavin MJ, Koslov S, Shiloh Y and Barcellos-Hoff MH. Inhibition of transforming growth factor-betal signaling attenuates ataxia telangiectasia mutated activity in response to genotoxic stress. Cancer Res. 2006; 66:10861-10869.

8. Glick A, Popescu N, Alexander V, Ueno H, Bottinger E and Yuspa SH. Defects in transforming growth factorbeta signaling cooperate with a Ras oncogene to cause rapid aneuploidy and malignant transformation of mouse keratinocytes. Proc Natl Acad Sci U S A. 1999; 96:1494914954

9. Mishra L, Derynck R and Mishra B. Transforming growth factor-beta signaling in stem cells and cancer. Science. 2005; 310:68-71.

10. Bornstein S, White R, Malkoski S, Oka M, Han G, Cleaver T, Reh D, Andersen P, Gross N, Olson S, Deng C, Lu SL and Wang XJ. Smad4 loss in mice causes spontaneous head and neck cancer with increased genomic instability and inflammation. J Clin Invest. 2009; 119:3408-3419.

11. Tang Y, Katuri V, Dillner A, Mishra B, Deng CX and Mishra L. Disruption of transforming growth factor-beta signaling in ELF beta-spectrin-deficient mice. Science. 2003; 299:574-577.

12. Kitisin K, Ganesan N, Tang Y, Jogunoori W, Volpe EA, Kim SS, Katuri V, Kallakury B, Pishvaian M, Albanese C, Mendelson J, Zasloff M, Rashid A, Fishbein T, Evans SR, Sidawy A, et al. Disruption of transforming growth factor-beta signaling through beta-spectrin ELF leads to hepatocellular cancer through cyclin D1 activation. Oncogene. 2007; 26:7103-7110.

13. Bennett V and Healy J. Organizing the fluid membrane bilayer: diseases linked to spectrin and ankyrin. Trends Mol Med. 2008; 14:28-36.

14. Husi H, Ward MA, Choudhary JS, Blackstock WP and Grant SG. Proteomic analysis of NMDA receptor-adhesion protein signaling complexes. Nat Neurosci. 2000; 3:661669.

15. Sridharan D, Brown M, Lambert WC, McMahon LW and Lambert MW. Nonerythroid alphaII spectrin is required for recruitment of FANCA and XPF to nuclear foci induced by DNA interstrand cross-links. J Cell Sci. 2003; 116:823-835.

16. Tang Y, Kitisin K, Jogunoori W, Li C, Deng CX, Mueller SC, Ressom HW, Rashid A, He AR, Mendelson JS, Jessup JM, Shetty K, Zasloff M, Mishra B, Reddy EP, Johnson L, et al. Progenitor/stem cells give rise to liver cancer due to aberrant TGF-beta and IL-6 signaling. Proc Natl Acad Sci U S A. 2008; 105:2445-2450.

17. Kanzler S, Meyer E, Lohse AW, Schirmacher P, Henninger J, Galle PR and Blessing M. Hepatocellular expression of a dominant-negative mutant TGF-beta type II receptor accelerates chemically induced hepatocarcinogenesis. Oncogene. 2001; 20:5015-5024.

18. Romero-Gallo J, Sozmen EG, Chytil A, Russell WE, Whitehead R, Parks WT, Holdren MS, Her MF, Gautam S, Magnuson M, Moses HL and Grady WM. Inactivation of TGF-beta signaling in hepatocytes results in an increased proliferative response after partial hepatectomy. Oncogene. 2005; 24:3028-3041.

19. Pandita TK, Pathak S and Geard CR. Chromosome end associations, telomeres and telomerase activity in ataxia telangiectasia cells. Cytogenet Cell Genet. 1995; 71:86-93.

20. Pandita RK, Sharma GG, Laszlo A, Hopkins KM, Davey S, Chakhparonian M, Gupta A, Wellinger RJ, Zhang J, Powell SN, Roti Roti JL, Lieberman HB and Pandita TK. Mammalian Rad9 plays a role in telomere stability, S- and G2-phase-specific cell survival, and homologous recombinational repair. Mol Cell Biol. 2006; 26:1850-1864.

21. Pandita TK and Hittelman WN. Initial chromosome damage but not DNA damage is greater in ataxia telangiectasia cells. Radiat Res. 1992; 130:94-103.

22. Freyer GA, Palmer DA, Yu Y, Miller RC and Pandita TK. Neoplastic transformation of mouse C3H10T1/2 cells following exposure to neutrons does not involve mutation of ras gene as analyzed by SSCP and cycle sequencing. Mutat Res. 1996; 357:237-244.

23. Gupta A, Hunt CR, Hegde ML, Chakraborty S, Udayakumar D, Horikoshi N, Singh M, Ramnarain DB, Hittelman WN, Namjoshi S, Asaithamby A, Hazra TK, Ludwig T, Pandita RK, Tyler JK and Pandita TK. MOF Phosphorylation by ATM Regulates 53BP1-Mediated Double-Strand Break Repair Pathway Choice. Cell Rep. 2014; 8:177-189.

24. Gupta A, Guerin-Peyrou TG, Sharma GG, Park C, Agarwal M, Ganju RK, Pandita S, Choi K, Sukumar S, Pandita RK, Ludwig T and Pandita TK. The mammalian ortholog of Drosophila MOF that acetylates histone H4 lysine 16 is essential for embryogenesis and oncogenesis. Mol Cell Biol. 2008; 28:397-409.

25. Singh M, Hunt CR, Pandita RK, Kumar R, Yang CR, Horikoshi N, Bachoo R, Serag S, Story MD, Shay JW, Powell SN, Gupta A, Jeffery J, Pandita S, Chen BP, Deckbar D, et al. Lamin a/c depletion enhances DNA damage-induced stalled replication fork arrest. Molecular and cellular biology. 2013; 33:1210-1222.

26. Paull TT, Rogakou EP, Yamazaki V, Kirchgessner CU, Gellert $\mathrm{M}$ and Bonner WM. A critical role for histone H2AX in recruitment of repair factors to nuclear foci after DNA damage. Curr Biol. 2000; 10:886-895.

27. Pandita TK and Richardson C. Chromatin remodeling finds its place in the DNA double-strand break response. Nucleic Acids Res. 2009; 37:1363-1377.

28. Scott SP and Pandita TK. The cellular control of DNA double-strand breaks. J Cell Biochem. 2006; 99:1463-1475.

29. Hunt CR, Ramnarain D, Horikoshi N, Iyengar P, Pandita RK, Shay JW and Pandita TK. Histone modifications and 
DNA double-strand break repair after exposure to ionizing radiations. Radiation research. 2013; 179:383-392.

30. Morales JC, Xia Z, Lu T, Aldrich MB, Wang B, Rosales C, Kellems RE, Hittelman WN, Elledge SJ and Carpenter PB. Role for the BRCA1 C-terminal repeats (BRCT) protein 53BP1 in maintaining genomic stability. J Biol Chem. 2003; 278:14971-14977.

31. Ward IM, Minn K, van Deursen J and Chen J. p53 Binding protein 53BP1 is required for DNA damage responses and tumor suppression in mice. Molecular and cellular biology. $2003 ; 23: 2556-2563$.

32. Zimmermann M, Lottersberger F, Buonomo SB, Sfeir A and de Lange T. 53BP1 regulates DSB repair using Rif1 to control 5' end resection. Science. 2013; 339:700-704.

33. Gupta A, Hunt CR, Chakraborty S, Pandita RK, Yordy J, Ramnarain DB, Horikoshi N and Pandita TK. Role of 53BP1 in the Regulation of DNA Double-Strand Break Repair Pathway Choice. Radiation research. 2014; 181:1-8.

34. Chapman JR, Barral P, Vannier JB, Borel V, Steger M, Tomas-Loba A, Sartori AA, Adams IR, Batista FD and Boulton SJ. RIF1 is essential for 53BP1-dependent nonhomologous end joining and suppression of DNA double-strand break resection. Molecular cell. 2013; 49:858-871.

35. Di Virgilio M, Callen E, Yamane A, Zhang W, Jankovic M, Gitlin AD, Feldhahn N, Resch W, Oliveira TY, Chait BT, Nussenzweig A, Casellas R, Robbiani DF and Nussenzweig MC. Rif1 prevents resection of DNA breaks and promotes immunoglobulin class switching. Science. 2013; 339:711715.

36. Escribano-Diaz C and Durocher D. DNA repair pathway choice - a PTIP of the hat to 53BP1. EMBO Rep. 2013; 14:665-666.

37. Feng L, Fong KW, Wang J, Wang W and Chen J. RIF1 counteracts BRCA1-mediated end resection during DNA repair. J Biol Chem. 2013; 288:11135-11143.

38. Bunting SF, Callen E, Wong N, Chen HT, Polato F, Gunn A, Bothmer A, Feldhahn N, Fernandez-Capetillo O, Cao L, $\mathrm{Xu}$ X, Deng CX, Finkel T, Nussenzweig M, Stark JM and Nussenzweig A. 53BP1 inhibits homologous recombination in Brca1-deficient cells by blocking resection of DNA breaks. Cell. 2010; 141:243-254.

39. Deans AJ and West SC. DNA interstrand crosslink repair and cancer. Nat Rev Cancer. 2011; 11:467-480.

40. Hunt CR, Dix DJ, Sharma GG, Pandita RK, Gupta A, Funk $\mathrm{M}$ and Pandita TK. Genomic instability and enhanced radiosensitivity in Hsp70.1- and Hsp70.3-deficient mice. Mol Cell Biol. 2004; 24:899-911.

41. Gupta A, Sharma GG, Young CS, Agarwal M, Smith ER, Paull TT, Lucchesi JC, Khanna KK, Ludwig T and Pandita TK. Involvement of human MOF in ATM function. Mol Cell Biol. 2005; 25:5292-5305.

42. Sharma GG, Hwang KK, Pandita RK, Gupta A, Dhar S, Parenteau J, Agarwal M, Worman HJ, Wellinger RJ and
Pandita TK. Human heterochromatin protein 1 isoforms HP1(Hsalpha) and HP1(Hsbeta) interfere with hTERTtelomere interactions and correlate with changes in cell growth and response to ionizing radiation. Mol Cell Biol. 2003; 23:8363-8376.

43. Kim SB, Pandita RK, Eskiocak U, Ly P, Kaisani A, Kumar R, Cornelius C, Wright WE, Pandita TK and Shay JW. Targeting of Nrf2 induces DNA damage signaling and protects colonic epithelial cells from ionizing radiation. Proc Natl Acad Sci U S A. 2012; 109:E2949-2955.

44. Jacquet K, Fradet-Turcotte A, Avvakumov N, Lambert JP, Roques C, Pandita RK, Paquet E, Herst P, Gingras AC, Pandita TK, Legube G, Doyon Y, Durocher D and Cote J. The TIP60 Complex Regulates Bivalent Chromatin Recognition by 53BP1 through Direct H4K20me Binding and H2AK15 Acetylation. Mol Cell. 2016; 62:409-421.

45. Nicolette ML, Lee K, Guo Z, Rani M, Chow JM, Lee SE, Paull TT. Mre11-Rad50-Xrs2 and Sae2 promote 5' strand resection of DNA double-strand breaks. Nat Struct Mol Biol. 2010;17:1478-1485.

46. Zhou Y, Caron P, Legube G and Paull TT. Quantitation of DNA double-strand break resection intermediates in human cells. Nucleic Acids Res. 2014; 42:e19.

47. Rodrigue A, Lafrance M, Gauthier MC, McDonald D, Hendzel M, West SC, Jasin M and Masson JY. Interplay between human DNA repair proteins at a unique doublestrand break in vivo. EMBO J. 2006; 25:222-231.

48. Sharma GG, So S, Gupta A, Kumar R, Cayrou C, Avvakumov N, Bhadra U, Pandita RK, Porteus MH, Chen DJ, Cote J and Pandita TK. MOF and histone H4 acetylation at lysine 16 are critical for DNA damage response and double-strand break repair. Mol Cell Biol. 2010; 30:35823595 .

49. Pierce AJ, Johnson RD, Thompson LH and Jasin M. XRCC3 promotes homology-directed repair of DNA damage in mammalian cells. Genes Dev. 1999; 13:26332638 .

50. Moses HL, Yang EY and Pietenpol JA. TGF-beta stimulation and inhibition of cell proliferation: new mechanistic insights. Cell. 1990; 63:245-247.

51. Michalopoulos GK and DeFrances MC. Liver regeneration. Science. 1997; 276:60-66.

52. Im YH, Kim HT, Kim IY, Factor VM, Hahm KB, Anzano M, Jang JJ, Flanders K, Haines DC, Thorgeirsson SS, Sizeland A and Kim SJ. Heterozygous mice for the transforming growth factor-beta type II receptor gene have increased susceptibility to hepatocellular carcinogenesis. Cancer Res. 2001; 61:6665-6668.

53. Thenappan A, Shukla V, Abdul Khalek FJ, Li Y, Shetty K, Liu P, Li L, Johnson RL, Johnson L and Mishra L. Loss of transforming growth factor beta adaptor protein beta-2 spectrin leads to delayed liver regeneration in mice. Hepatology. 2011; 53:1641-1650.

54. Ewan KB, Henshall-Powell RL, Ravani SA, Pajares MJ, 
Arteaga C, Warters R, Akhurst RJ and Barcellos-Hoff MH. Transforming growth factor-beta1 mediates cellular response to DNA damage in situ. Cancer Res. 2002; 62:5627-5631.

55. Chen CL, Tsukamoto H, Liu JC, Kashiwabara C, Feldman D, Sher L, Dooley S, French SW, Mishra L, Petrovic L, Jeong JH and Machida K. Reciprocal regulation by TLR4 and TGF-beta in tumor-initiating stem-like cells. J Clin Invest. 2013; 123:2832-2849.

56. Bouwman P, Aly A, Escandell JM, Pieterse M, Bartkova J, van der Gulden H, Hiddingh S, Thanasoula M, Kulkarni A, Yang Q, Haffty BG, Tommiska J, Blomqvist C, Drapkin R, Adams DJ, Nevanlinna H, et al. 53BP1 loss rescues BRCA1 deficiency and is associated with triple-negative and BRCA-mutated breast cancers. Nat Struct Mol Biol. 2010; 17:688-695.

57. Tang J, Cho NW, Cui G, Manion EM, Shanbhag NM, Botuyan MV, Mer G and Greenberg RA. Acetylation limits 53BP1 association with damaged chromatin to promote homologous recombination. Nat Struct Mol Biol. 2013; 20:317-325.

58. Zhi X, Lin L, Yang S, Bhuvaneshwar K, Wang H, Gusev Y, Lee MH, Kallakury B, Shivapurkar N, Cahn K, Tian X, Marshall JL, Byers SW and He AR. betaII-Spectrin (SPTBN1) suppresses progression of hepatocellular carcinoma and Wnt signaling by regulation of Wnt inhibitor kallistatin. Hepatology. 2015; 61:598-612.

59. Scherthan H, Jerratsch M, Dhar S, Wang YA, Goff SP and Pandita TK. Meiotic telomere distribution and Sertoli cell nuclear architecture are altered in Atm- and Atm-p53deficient mice. Mol Cell Biol. 2000; 20:7773-7783.

60. Pandita TK, Westphal CH, Anger M, Sawant SG, Geard CR, Pandita RK and Scherthan H. Atm inactivation results in aberrant telomere clustering during meiotic prophase. Mol Cell Biol. 1999; 19:5096-5105.

61. Gupta A, Yang Q, Pandita RK, Hunt CR, Xiang T, Misri
S, Zeng S, Pagan J, Jeffery J, Puc J, Kumar R, Feng Z, Powell SN, Bhat A, Yaguchi T, Wadhwa R, et al. Cell cycle checkpoint defects contribute to genomic instability in PTEN deficient cells independent of DNA DSB repair. Cell Cycle. 2009; 8:2198-2210.

62. Gupta A, Hunt CR, Pandita RK, Pae J, Komal K, Singh M, Shay JW, Kumar R, Ariizumi K, Horikoshi N, Hittelman WN, Guha C, Ludwig T and Pandita TK. T-cell-specific deletion of Mof blocks their differentiation and results in genomic instability in mice. Mutagenesis. 2013; 28:263270.

63. Pandita TK and Geard CR. Chromosome aberrations in human fibroblasts induced by monoenergetic neutrons. I. Relative biological effectiveness. Radiat Res. 1996; 145:730-739.

64. Pandita TK. Effect of temperature variation on sister chromatid exchange frequency in cultured human lymphocytes. Hum Genet. 1983; 63:189-190.

65. Pandita TK. Assessment of the mutagenic potential of a fungicide Bavistin using multiple assays. Mutat Res. 1988; 204:627-643.

66. Torres MJ, Pandita RK, Kulak O, Kumar R, Formstecher E, Horikoshi N, Mujoo K, Hunt CR, Zhao Y, Lum L, Yeaman C, White M and Pandita TK. Role of the Exocyst complex component Sec6/8 in genomic stability. Mol Cell Biol. 2015; 35:3633-45. doi: 10.1128/MCB.00768-15.. 